\title{
Does Perceived Value Mediate the Relationship between Service Traits and Client Satisfaction in the Software-as-a-Service (SaaS)?
}

\author{
J. W. Liu ${ }^{1}$, Jamie Y. T. Chang ${ }^{2}$, Jacob C. A. Tsai ${ }^{3}$, James J. Jiang ${ }^{3}$ \\ ${ }^{1}$ Digital of Game and Animation Design, Taipei College of Maritime Technology, Taipei City, Chinese Taipei \\ ${ }^{2}$ Department of Information Management, Tunghai University, Taichung, Chinese Taipei \\ ${ }^{3}$ Department of Business Administration, College of Management, National Taiwan University, Taipei City, \\ Chinese Taipei \\ Email: jwliu99@gmail.com, ${ }^{*}$ jamie@thu.edu.tw, jijiang@ntu.edu.tw
}

Received 8 June 2015; accepted 7 July 2015; published 14 July 2015

\begin{abstract}
The Software-as-a-Service (SaaS) product model provides clients to outsource software application processing requirements. Customer satisfaction is an important problem facing SaaS firms. Marketing theory suggests that customer satisfaction is affected by perceived value, but this relationship has not been examined in the SaaS context. This study argues for the mediating role of perceived value in the relationship between traits of the SaaS product and customer satisfaction. Our model builds on prior studies and success theories to consider whether service quality, service response, security, and information quality are mediated in their relationship to customer satisfaction. This study posits that perceived value serves as the primary mediator and trust as a controlling mediator in a model tested using a survey of ASP client firms.
\end{abstract}

\section{Keywords}

Software-as-a-Service, IT Outsourcing, Service Quality, Satisfaction, Perceived Value, Trust

\section{Introduction}

The Software-as-a-Service (SaaS) product model allows clients to outsource software application processing requirements. For a periodic fee, a client gains access to a variety of software applications and services that will otherwise be too expensive or complicated to administer internally or purchase outright (Gartner, 2011) [1]. The flexibility and currency of SaaS products lead to an ever increasing demand, with spending on SaaS offerings forecasted to grow to $\$ 258$ billion by 2020 (Forrester, 2011) [2]. However, limited customization capability and ample competing products across venders mean that retaining clients is not an easy task (Ahmad and Dey, 2012)

"Corresponding author.

How to cite this paper: Liu, J.W., Chang, J.Y.T., Tsai, J.C.A. and Jiang, J.J. (2015) Does Perceived Value Mediate the Relationship between Service Traits and Client Satisfaction in the Software-as-a-Service (SaaS)? Open Journal of Social Sciences, 3, 159-165. http://dx.doi.org/10.4236/iss.2015.37026 
[3]. Venders must frequently upgrade SaaS services and demonstrate sufficient information security and privacy safeguards (Levina and Ross, 2003) [4]. To retain clients in this turbulent environment, client satisfaction is a key competitive advantage (Benlian et al., 2011) [5]. It is essential that venders understand the formation of client satisfaction so critical to the SaaS business model. In the context of outsourced software applications, researchers examine the relationship between service provisions and client satisfaction (Benlian et al., 2011; Susarla and Barua, 2003) [5] [6]. These studies reveal insightful lessons about critical service features that include service quality, security, information quality, and service responsiveness. They reinforce conventional wisdom that maintains good quality service and customer satisfaction must be achieved by SaaS venders (Forrester, 2011) [2]. Further, to maintain essential and long-term relationships with clients requires the building of trust between clients and venders (Chou and Chiang, 2013) [7]. SaaS venders must earn client trust by continually providing high service quality (Benlian et al., 2011) [5]. In this line of thought, trust directly impacts client satisfaction while traits of service fulfilment become critical to the attainment of trust, introducing a mediator in the relationship.

While not denying the role of trust, the marketing literature expressly puts perceived value as a key driver of client satisfaction (Eggert, 2002; Lam et al., 2004) [8] [9]. In simplistic terms, perceived value for a client means that after utilizing a service, they feel better off than before (Grönroos, 2008) [10]. However, the relationships among SaaS features, perceived value, and client satisfaction are not cohesively considered. This study therefore aims to explore the research question-does perceived value mediate the relationship between service traits and client satisfaction in the SaaS context?

\section{Literature Review}

\section{Software-as-a-Service (SaaS)}

The Software-as-a-Service model allows businesses to outsource some or all of their IT processing to another firm. The SaaS model has its origins in traditional IT and business process outsourcing (Blaskovich and Mintchik, 2011) [11]. Similar to application service provision (ASP) arrangements, and spurred by the availability of high-speed networking, distributed computing facilities, and convergent technology platforms (Benlian et al., 2011) [5], the contemporary SaaS model involves substituting the SaaS partner for many of the conventional IT services that ordinarily exist inside the firm (Valente and Mitra, 2007) [12]. As such, SaaS differs from ASP mostly in the technology, platforms, and business models and not in the types of services. The SaaS provider becomes responsible for contracted IT services, in effect substituting their function for internal systems within the client organization. Maintaining good quality service and customer satisfaction is hence a vital task facing SaaS managers (Forrester, 2011) [2]. To remain viable businesses, venders must struggle to identify and preserve client satisfaction to remain successful (Lacity et al., 2009) [13].

One critical difference between the SaaS model and familiar IT outsourcing is that, in the SaaS context, the principal is typically separate and disconnected from the outsourcing agent. This separation has led to research into the contractual control and monitoring effects of SaaS agreements, which are typically more fleeting and have a narrower scope than traditional outsourcing (Goo et al., 2009; Singh et al., 2004) [14] [15]. Under such a model, a SaaS client is able to leave the relationship more easily. The network-enabled separation in the SaaS model must be seen in the context of an IT success relationship, similar to the ASP model that adopts IT success models to explain success rather than adopting outsourcing success factors (Landrum and Prybutok, 2004) [16]. The key ASP success factors include information quality (Bryson and Ngwenyama, 2000) [17] and service responsiveness (Huang et al., 2011; Mani et al., 2010) [18] [19]. Recent literature suggests these factors to hold, but has dismissed system quality as a factor in the ASP context (Lee et al., 2007; Negash et al., 2003) [20] [21]. Unfortunately, these studies typically examine one individual attribute at a time.

\section{Research Model}

Elements of satisfaction can be viewed as cognitive-based, affective-based or both. McKinney et al. (2002) [22] claim that satisfaction is "an effective staterepresenting an emotional response" to a product or service. In SaaS, satisfaction is an affective state resulting from the client's evaluation of the service applications provided by vendor. Satisfaction has been a useful indicator of system success in many prior IS studies (Delone, 2003; DeLone and McLean, 1992) [23] [24], because satisfied users are more likely to engage in effective system use (Li 
and Gregor, 2001) [25], and hold SaaS continuance intentions (Benlian et al., 2011) [5]. Satisfaction arises from identifying and meeting the client's requirements (Kern and Willcocks, 2000) [26], which is fostered by a close relationship between the client and the vender (Kakabadse and Kakabadse, 2002) [27]. A link between service quality factors and satisfaction is rooted in IS models (Delone, 2003) [23]. The user will increase their satisfaction with a high level of service quality. This relationship has been confirmed not only in individual acceptance of technology but also in SaaS success (e.g., Benlian et al., 2011) [5].

The role of perceived value provides an enhanced theoretical lens to understand why clients are satisfied with a particular technology (Kim et al., 2013) [28]. For example, perceived value was the strongest predictor of satisfaction in Lai's model of mobile device service (Lai, 2004) [29]. Clients tend to be satisfied with a service when they find the service is valuable, even though they are unable to confirm their expectation during the service delivery process (Lin et al., 2012) [30]. SaaS is a value-added service. When clients receive SaaS services from providers, they expect the service offered to meet or exceed requirements. Perceived value drives satisfaction in many contexts and should not differ in the SaaS context. Based on our understanding of value and satisfaction in the IS success literature and marketing literature, we propose the theoretical model shown in Figure 1.

\section{Research Hypotheses}

Security is a significant problem facing many online services. Threats to security include data theft, extortion, hacking, process vulnerabilities, and employee and customer fraud (Salisbury et al., 2011) [31]. These threats can adversely affect operations by compromising the data, services and companies involved. In the outsourcing context, security of business operations has been a critical concern for decades because of the displacement and relocation of operational control inherent in outsourcing arrangements (Martinsons, 1993) [32]. To preserve business continuity, the SaaS provider must enact a raft of security measures. Though security mechanisms for online services are typically complex and highly interwoven, the client must be aware of those security mechanisms that directly affect their own safety. Venders that are perceived to provide greater security should, therefore, be perceived to deliver greater benefits to the client adding to the value perception. Prior studies in closely related situations support the argument that superior security procedures improve the perceived value of the service and identify security as a critical factor (Ma et al., 2005) [33]. Poor security is a barrier to engaging with a vender (Jeong and Stylianou, 2010) [34]. This discussion leads to the second hypothesis:

\section{H1: SaaS vender security has a positive influence on perceived value}

Service response is a degree of flexibility to client requests with regard to service changes. Service response is a critical factor for SaaS venders who must respond to the changing needs of the clients as in other outsourcing arrangements (Singh et al., 2004) [15]. Any lack of response may harm the client in terms of its business operations and results in a potentially harmful lack of operational control (Rustagi et al., 2008) [35]. A client firm may feel less able to make important changes (Daugherty et al., 1995) [36]. Client requirements for software

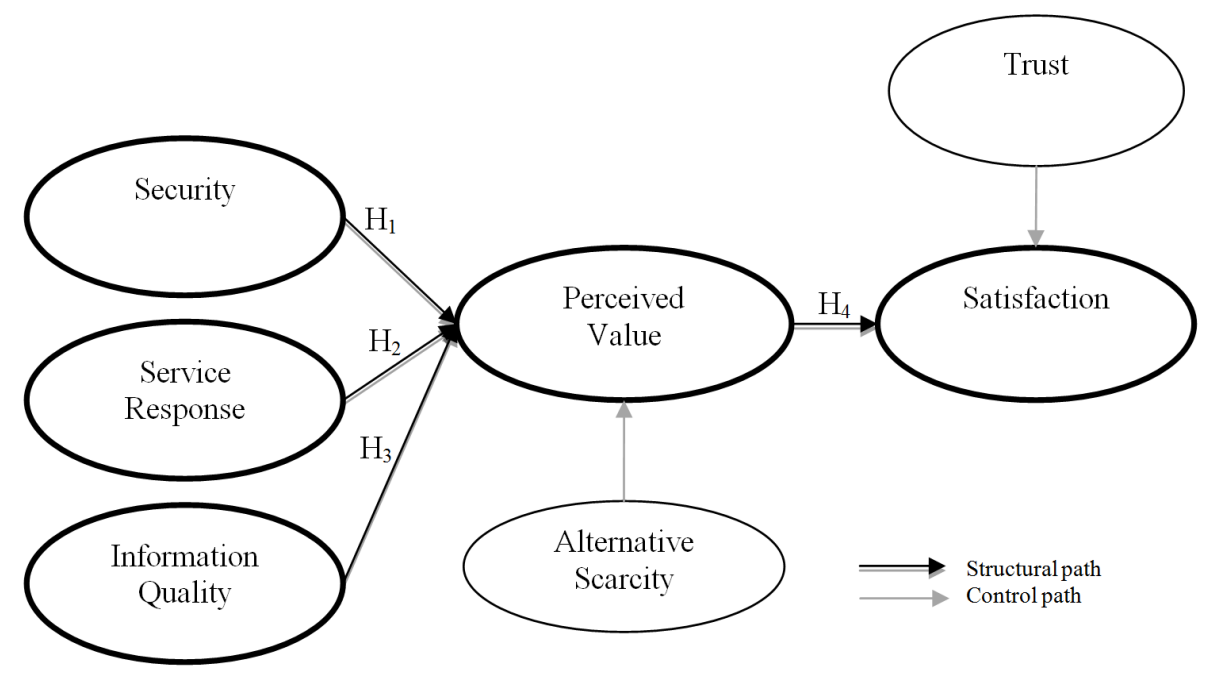

Figure 1. Theoretical model. 
service provider agility may vary depending on the business problem at hand, however the on-demand nature of these IT services is characterized by frequent service exchanges throughout the relationship (Smith andKumar, 2004) [37]. Agility is an important requirement for effectively supporting client needs when these needs may change quickly (Kim et al., 2011) [38]. Though software service providers benefit from economies of scale by supporting as many clients as possible while minimizing the cost and effort of customizing packages, it will still be advantageous to provide the benefits of rapid responses to requests (Smith and Rupp, 2002) [39]. Prompt service response improves these control perceptions, in turn allowing the client to continue with its operations without hindrance, thereby improving perceived value and use (Smith and Kumar, 2004) [37]. Thus, our third hypothesis:

\section{H2: SaaS provider service response has a positive influence on perceived value}

The outputs of an information system must improve and support decision-making at targeted levels in an organization (Gelman, 2010) [40]. Good quality information is beneficial to those making decisions and conducting operations (Moreau, 2006) [41]. In an outsourcing context, quality information contributes to positive perceptions of the ongoing relationship between the client and vender (Yoon and Im, 2005) [42]. In the SaaS context, the client must rely heavily on the information made available by the service provider (Schumann et al., 2012) [43]. These information outputs are important to the client because they provide insight into the health of their operations and direction for decisions (Sigala, 2004) [44]. Similarly, if the information they receive is of bad quality, the client possesses few alternative sources for this information because they have replaced the relevant internal services with those of the SaaS provider. For these reasons, high quality information will be a valuable service adding to perceived value. This leads to our fourth hypothesis:

\section{H3: SaaS provider information quality has a positive influence on perceived value}

Prior research in the outsourcing literature emphasized the role of satisfaction in the client-provider relationship and considered it an important measure of IS success in SaaS services (Chou et al., 2013) [7]. The literature expresses the differences and relationship between perceived value and satisfaction. Perceived value is a cognition-based construct capturing any benefit-cost discrepancy, whereas customer satisfaction is primarily an affective and evaluative response (Oliver, 1996) [45]. When client preferences are met, they are likely to perceive greater value in the origin of those services (Flint et al., 2011) [46]. In turn, this perceived value assessment will increase their level of satisfaction in the service provider. The service management literature argues that customer satisfaction is the result of a customer's perception of the value received in a transaction or relationship (Heskett et al., 1990) [47]. DeLone and McLean (2003) [23] explain user satisfaction is the extent to which a system application facilitates the user to create value for the organizational customers. The social science literature indicates that cognitive thought processes trigger affective responses (Weiner, 1986) [48], suggesting that customer value judgments affect perceptions of satisfaction. Thus, we posit our final hypothesis:

\section{H4: Perceived value has a positive influence on satisfaction}

In addition to our five research hypotheses, our conceptualization of SaaS satisfaction also features two control variables. First, Alternative Scarcity describes the perceived rarity of alternative SaaS providers in the market. The availability of alternative SaaS providers means that a client firm is not bound to a single service provider. If there are no alternative SaaS providers in the market, the client firm may have no reference or benchmark against which to compare their service levels and may be unable to gauge the value of their current SaaS provider. We hence add the Availability of Alternatives as a control variable to perceived value in our model. Second, we control for the effect of trust on satisfaction. Trust describes a perception on the part of the client that the SaaS provider is truthful and interested in mutual welfare. Prior literature emphasized the importance of trust in business partnerships and outsourcing arrangements which involve close working relationships between firms (Bachmann and Inkpen, 2011) [49]. SaaS arrangements involve access to sensitive processes and resources, and the client must trust the vender to protect sensitive resources and not use them for gain. Trust is considered to be a strong indicator of satisfaction that is also effected by service factors in the SaaS context (Chou and Chiang, 2013) [7]. We, therefore, position trust as a second potential mediator in the path from service factors to satisfaction to control for this alternate explanation.

\section{Research Method}

A survey will be chosen as the most appropriate data gathering method to address the research question as modelled in Figure 1. The method is oft applied in information systems research, especially for studies that quantita- 
tively explore the interaction of a range of variables (Newsted et al., 1998) [50]. An introduction letter to the questionnaire requested confirmation that the recipient had experience with more than one SaaS vender: Key informants should have more than one SaaS provider in their organizations and they should have influence in the selection of SaaS venders. The respondents with sufficient experience can better capture the aspects of cost and benefit that are relevant to the value of SaaS service. The influence in SaaS selection assures an authority to represent the organization-yielding authority to the individual perceptions of the respondent.

\section{Expected Contributions}

This study aims to extend prior understanding of client satisfaction in the SaaS context. Using prior literature in the marketing field, we advanced an explanation of satisfaction that was predicated on the perceived value of SaaS services as a mediating variable. Based on prior literature in the area of ASP success, we address four antecedent success factors: Service Quality, Security, Service Response and Information Quality. This study provides evidence of the mediating role of perceived value in the SaaS context, thereby enhancing satisfaction toward an IT application service provider. In particular, the adoption of perceived value as a mediator between various service features and user satisfaction provides an integrated model to incorporate success factors as antecedents and offer new insight to our understanding of how important service features collectively impact a client's perceived value. We expect that trust is a significant predictor of satisfaction from our survey results. This study contributes to knowledge in three ways. First, it enhances our understanding of the critical indicators of attaining desirable states of trust and perceived value. Second, the study extends existing satisfaction models in the application services arena (Susarla et al., 2003) [6] by incorporating two mediating factors-perceived value and trust. Third, the results will provide an indication of the more important predictor of satisfaction in the SaaS arena to help direct future studies and boardroom discussions. The outcomes of this study will provide several important implications for IT outsourcing research.

\section{References}

[1] Gartner (2011) Evaluating Cloud Infrastructure as a Service. In: Leong, L., Ed., Gartner.

[2] Forrester (2011) The Forrester Wave ${ }^{\mathrm{TM}}$ : Global IT Infrastructure Outsourcing. In: Martorelli, B. and Benkel, W., Eds., The Forrester Wave ${ }^{\mathrm{TM}}$, Forrester Research.

[3] Ahmad, A., Dey, L. and Halawani, S.M. (2012) A Rule-Based Method for Identifying the Factor Structure in Customer Satisfaction. Information Sciences, 198, 118-129. http://dx.doi.org/10.1016/j.ins.2012.02.056

[4] Levina, N. and Ross, J.W. (2003) From the Vendor's Perspective: Exploring the Value Proposition in Information Technology Outsourcing. MIS Quarterly, 27, 331-364.

[5] Benlian, A., Koufaris, M. and Hess, T. (2011) Service Quality in Software-as-a-Service: Developing the SaaS-Qual Measure and Examining Its Role in Usage Continuance. Journal of Management Information Systems, 28, 85-126. http://dx.doi.org/10.2753/MIS0742-1222280303

[6] Susarla, A., Barua, A. and Whinston, A.B. (2003) Understanding the Service Component of Application Service Provision: Empirical Analysis of Satisfaction with ASP Services. MIS Quarterly, 27, 91-123.

[7] Chou, S.-W. and Chiang, C.-H. (2013) Understanding the Formation of Software-as-a-Service (SaaS) Satisfaction from the Perspective of Service Quality. Decision Support Systems, 56, 148-155. http://dx.doi.org/10.1016/j.dss.2013.05.013

[8] Eggert, A. and Ulaga, W. (2002) Customer Perceived Value: A Substitute for Satisfaction in Business Markets? Journal of Business \& Industrial Marketing, 17, 107-118. http://dx.doi.org/10.1108/08858620210419754

[9] Lam, S.Y., Shankar, V., Erramilli, M.K. and Murthy, B. (2004) Customer Value, Satisfaction, Loyalty, and Switching Costs: An Illustration from a Business-to-Business Service Context. Journal of the Academy of Marketing Science, 32, 293-311. http://dx.doi.org/10.1177/0092070304263330

[10] Grönroos, C. (2008) Service Logic Revisited: Who Creates Value? And Who Co-Creates? European Business Review, 20, 298-314. http://dx.doi.org/10.1108/09555340810886585

[11] Blaskovich, J. and Mintchik, N. (2011) Information Technology Outsourcing: A Taxonomy of Prior Studies and Directions for Future Research. Journal of Information Systems, 25, 1-36. http://dx.doi.org/10.2308/jis.2011.25.1.1

[12] Valente, P. and Mitra, G. (2007) The Evolution of Web-Based Optimisation: From ASP to e-Services. Decision Support Systems, 43, 1096-1116. http://dx.doi.org/10.1016/j.dss.2005.07.003

[13] Lacity, M.C., Khan, S.A. and Willcocks, L.P. (2009) A Review of the IT Outsourcing Literature: Insights for Practice. The Journal of Strategic Information Systems, 18, 130-146. http://dx.doi.org/10.1016/j.jsis.2009.06.002 
[14] Goo, et al. (2009)

[15] Singh, et al. (2004)

[16] Landrum, H. and Prybutok, V.R. (2004) A Service Quality and Success Model for the Information Service Industry. European Journal of Operational Research, 156, 628-642. http://dx.doi.org/10.1016/S0377-2217(03)00125-5

[17] Bryson, N. and Ngwenyama, O.K. (2000) Structuring IS Outsourcing Contracts for Mutual Gain: An Approach to Analyzing Performance Incentive Schemes. Journal of the Association for Information Systems, 1, 1-41.

[18] Huang, S., Zeng, S., Fan, Y. and Huang, G.Q. (2011) Optimal Service Selection and Composition for Service-Oriented Manufacturing Network. International Journal of Computer Integrated Manufacturing, 24, 416-430. http://dx.doi.org/10.1080/0951192X.2010.511657

[19] Mani, D., Barua, A. and Whinston, A. (2010) An Empirical Analysis of the Impact of Information Capabilities Design on Business Process Outsourcing Performance. MIS Quarterly, 34.

[20] Lee, S.M., Lee, H.-H., Kim, J. and Lee, S.-G. (2007) ASP System Utilization: Customer Satisfaction and User Performance. Industrial Management \& Data Systems, 107, 145-165. http://dx.doi.org/10.1108/02635570710723787

[21] Negash, S., Ryan, T. and Igbaria, M. (2003) Quality and Effectiveness in Web-Based Customer Support Systems. Information \& Management, 40, 757-768. http://dx.doi.org/10.1016/S0378-7206(02)00101-5

[22] McKinney, et al. (2002)

[23] Delone, W.H. (2003) The DeLone and McLean Model of Information Systems Success: A Ten-Year Update. Journal of Management Information Systems, 19, 9-30.

[24] DeLone, W.H. and McLean, E.R. (1992) Information Systems Success: The Quest for the Dependent Variable. Information Systems Research, 3, 60-95. http://dx.doi.org/10.1287/isre.3.1.60

[25] Li, M. and Gregor, S. (2011) Outcomes of Effective Explanations: Empowering Citizens through Online Advice. Decision Support Systems, 52, 119-132. http://dx.doi.org/10.1016/j.dss.2011.06.001

[26] Kern, T. and Willcocks, L. (2000) Exploring Information Technology Outsourcing Relationships: Theory and Practice. The Journal of Strategic Information Systems, 9, 321-350. http://dx.doi.org/10.1016/S0963-8687(00)00048-2

[27] Kakabadse, A. and Kakabadse, N. (2002) Trends in Outsourcing: Contrasting USA and Europe. European Management Journal, 20, 189-198. http://dx.doi.org/10.1016/S0263-2373(02)00029-4

[28] Kim, Y.H., Kim, D.J. and Wachter, K. (2013) A Study of Mobile User Engagement (MoEN): Engagement Motivations, Perceived Value, Satisfaction, and Continued Engagement Intention. Decision Support Systems, 56, 361-370. http://dx.doi.org/10.1016/j.dss.2013.07.002

[29] Lai, T.L. (2004) Service Quality and Perceived Value's Impact on Satisfaction, Intention and Usage of Short Message Service (SMS). Information Systems Frontiers, 6, 353-368. http://dx.doi.org/10.1023/B:ISFI.0000046377.32617.3d

[30] Lin, T.-C., Wu, S., Hsu, J.S.-C. and Chou, Y.-C. (2012) The Integration of Value-Based Adoption and Expectation-Confirmation Models: An Example of IPTV Continuance Intention. Decision Support Systems, 54, 63-75. http://dx.doi.org/10.1016/j.dss.2012.04.004

[31] Salisbury, D., Miller, D.W. and Turner, J.M. (2011) On Contending with Unruly Neighbors in the Global Village: Viewing Information Systems as Both Weapon and Target. Communications of the Association for Information Systems, $\mathbf{2 8}$.

[32] Martinsons, M.G. (1993) Outsourcing Information Systems: A Strategic Partnership with Risks. Long Range Planning, 26, 18-25. http://dx.doi.org/10.1016/0024-6301(93)90003-X

[33] Ma, Q., Pearson, J.M. and Tadisina, S. (2005) An Exploratory Study into Factors of Service Quality for Application Service Providers. Information \& Management, 42, 1067-1080. http://dx.doi.org/10.1016/j.im.2004.11.007

[34] Jeong, B.-K. and Stylianou, A.C. (2010) Market Reaction to Application Service Provider (ASP) Adoption: An Empirical Investigation. Information \& Management, 47, 176-187. http://dx.doi.org/10.1016/j.im.2010.01.007

[35] Rustagi, S., King, W.R. and Kirsch, L.J. (2008) Predictors of Formal Control Usage in IT Outsourcing Partnerships. Information Systems Research, 19, 126-143. http://dx.doi.org/10.1287/isre.1080.0169

[36] Daugherty, P.J., Ellinger, A.E. and Rogers, D.S. (1995) Information Accessibility: Customer Responsiveness and Enhanced Performance. International Journal of Physical Distribution \& Logistics Management, 25, 4-17. http://dx.doi.org/10.1108/09600039510080117

[37] Smith, M.A. and Kumar, R.L. (2004) A Theory of Application Service Provider (ASP) Use from a Client Perspective. Information \& Management, 41, 977-1002. http://dx.doi.org/10.1016/j.im.2003.08.019

[38] Kim, J., Hong, S., Min, J. and Lee, H. (2011) Antecedents of Application Service Continuance: A Synthesis of Satisfaction and Trust. Expert Systems with Applications, 38, 9530-9542. http://dx.doi.org/10.1016/j.eswa.2011.01.142

[39] Smith, A.D. and Rupp, W.T. (2002) Application Service Providers (ASP): Moving Downstream to Enhance Competi- 
tive Advantage. Information Management \& Computer Security, 10, 64-72. http://dx.doi.org/10.1108/09685220210424113

[40] Gelman, I.A. (2010) Setting Priorities for Data Accuracy Improvements in Satisficing Decision-Making Scenarios: A Guiding Theory. Decision Support Systems, 48, 507-520. http://dx.doi.org/10.1016/j.dss.2009.11.001

[41] Moreau, É.M.F. (2006) The Impact of Intelligent Decision Support Systems on Intellectual Task Success: An Empirical Investigation. Decision Support Systems, 42, 593-607. http://dx.doi.org/10.1016/j.dss.2005.02.008

[42] Yoon, Y. and Im, K.S. (2005) An Evaluation System for IT Outsourcing Customer Satisfaction Using the Analytic Hierarchy Process. Journal of Global Information Management, 13, 55-76. http://dx.doi.org/10.4018/jgim.2005100103

[43] Schumann, J.H., Wünderlich, N.V. and Wangenheim, F. (2012) Technology Mediation in Service Delivery: A New Typology and an Agenda for Managers and Academics. Technovation, 32, 133-143. http://dx.doi.org/10.1016/j.technovation.2011.10.002

[44] Sigala, M. (2004) The ASP-Qual Model: Measuring ASP Service Quality in Greece. Managing Service Quality, 14, 103-114. http://dx.doi.org/10.1108/09604520410513703

[45] Oliver, R.L. (1996) Varieties of Value in the Consumption Satisfaction Response. Advances in Consumer Research, 23.

[46] Flint, D.J., Blocker, C.P. and Boutin Jr., P.J. (2011) Customer Value Anticipation, Customer Satisfaction and Loyalty: An Empirical Examination. Industrial Marketing Management, 40, 219-230. http://dx.doi.org/10.1016/j.indmarman.2010.06.034

[47] Heskett, J.L., Sasser, W.E. and Hart, C.W.L. (1990) Service Breakthroughs: Changing the Rules of the Game. The Free Press, New York.

[48] Weiner, B. (1986) An Attributional Theory of Motivation and Emotion. Springer-Verlag, New York. http://dx.doi.org/10.1007/978-1-4612-4948-1

[49] Bachmann, R. and Inkpen, A.C. (2011) Understanding Institutional-Based Trust Building Processes in Inter-Organizational Relationships. Organization Studies, 32, 281-301. http://dx.doi.org/10.1177/0170840610397477

[50] Newsted, P.R., Huff, S.L. and Munro, M.C. (1998) Survey Instruments in Information Systems. MIS Quarterly, 22.

[51] Sabherwal, R. (1999) The Role of Trust in Outsourced IS Development Projects. Communications of the ACM, 42, 80-86. http://dx.doi.org/10.1145/293411.293485 